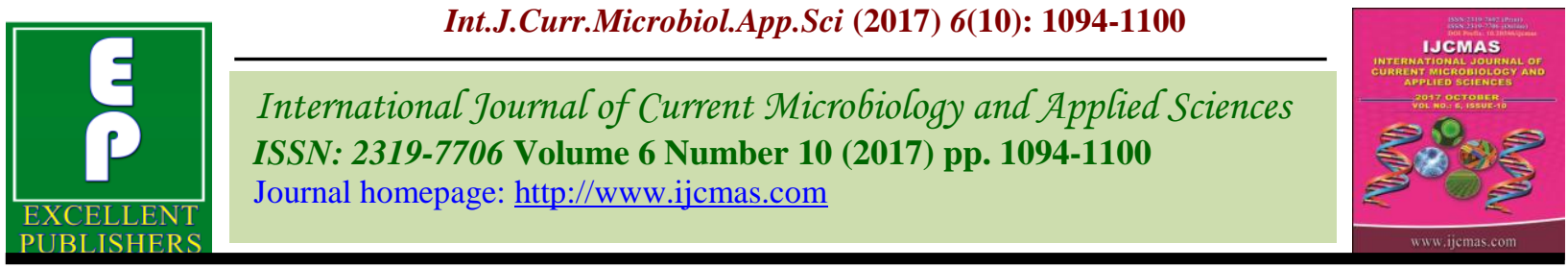

Original Research Article https://doi.org/10.20546/ijcmas.2017.610.133

\title{
Symptoms and Management of White Rust/ Blister of Indian Mustard (Albugo candida)
}

\author{
Abhishek, Rajendra Prasad, Dushyant Kumar, Virendra Kumar*, \\ Maneesh Kumar and Deepak Kumar
}

Department of Plant Pathology, C.S.A.U.A.T., Kanpur-208002, U.P., India

*Corresponding author

\author{
A B S T R A C T
}

\begin{tabular}{|l|}
\hline K e y w o r d s \\
Rapeseed-Mustard, \\
fungicide, Albugo \\
candida, Biotic, \\
Abiotic.
\end{tabular}

Mustard (Brassica juncea L.) belongs to Family Brassicaceae (Cruciferae) and genus Brassica. Albugo candida the causal organism of the white rust/ blister of the rapeseedmustard occurs in all parts of the world where cruciferous crops are grown. It is one of the important diseases of rapeseed-mustard in India causing a yield loss of 17-34 per cent. The use of resistant varieties is considered to be the best and cheapest method of managing the plant disease. Out of tested 30 genotype cultivars none was found free to this disease. Nine genotype viz., Bioysr and DRMRIJ-12-40, DRMR-2019, NDRE-08-14-01 and DRMRIJ12-40, were observed to be moderately resistant to the disease. Disease management evaluation of different fungicides, chemical with different combination The maximum yield viz., Single spray propiconazale 25EC (0.5\%), single spray metalaxyl $8 \%$ mencozeb $64 \% \mathrm{wp}(0.2 \%)$, single spray of hexaconazole $25 \mathrm{EC}(0.05 \%)$, single spray of difenconazole 25EC $(0.05 \%)$, single spray propiconazole $25 \mathrm{EL}(0.05 \%)$, T1 followed by $\mathrm{T} 2, \mathrm{~T} 1$ followed by $\mathrm{T} 1$, followed by $\mathrm{T} 4$, and $\mathrm{T} 1$ followed by $\mathrm{T} 5$. The maximum yield was obtained from single spray propiconazole $25 \mathrm{EL}(0.05 \%)$ treated plots.

\section{Introduction}

In India Rapeseed-Mustard is most important and predominant source of edible oil and raw material for industrial products. Rapeseedmustard is also world's third most important source of edible oil after soybean and oil palm. Mustard (Brassica juncea L.) belongs to family: Brassicaceae (Cruciferae) and genus Brassica. Total global area under rapeseed and mustard is about $26.09 \mathrm{~m}$ ha with total output of 571,880 tones of mustard at an average yield of 1-1.5 tons $\mathrm{ha}^{-1}$ (FAO, 2015) India is the fourth producer of mustard contributing to around $11 \%$ of world's total production. India produces around 65 lakh tonnes of mustard and around 26 lakh tonnes of mustard oil and 35 lakh tones oil cake. Rajasthan alone contributes $43 \%$ of the total mustard production in India.

Rapeseed and mustard are crops of temperate climates, but these can also be cultivated at higher elevations in the tropics. Crop requires about $18-25^{\circ} \mathrm{C}$ temperature, low humidity, practically no rains especially at the time of flowering. The crop growth is optimum at $<25^{\circ} \mathrm{C}$. 1 or 2 pre-flowering rains help in boosting the grain yield. Excessive cold and frost are harmful to the crop. Toria is more 
liable to suffer from frost and cold. Therefore, it is usually sown earlier, and harvested before the onset of frost. Rapeseed and mustard are long day in photo-periodic response. They require an annual precipitation of $40-100 \mathrm{~cm}$. These crops also do not tolerate water logging. Many biotic and abiotic stresses are responsible for reducing the production of mustard. White rust caused by Albugo candida Kuntze and Alternaria blight caused by Alternaria brassicae (Berk.) Sacc. have been reported to be most wide spread and destructive fungal diseases of rapeseedmustard throughout the world (Kolte, 1985).

In India, Symptoms of both these diseases on same leaves are quite common, while, combined infection of downy mildew and white rust on mustard have been observed rarely because of dry cool weather in this region. Yield losses from 23 to 54.5 per cent due to both phases (leaf and stag head) of white rust and from 17-48 per cent due to Alternaria blight have been reported from India (Saharan et al., 1984 and Saharan, 1991).

Albugo candida the causal organism of the white rust/ blister of the rapeseed- mustard occurs in all parts of the world where cruciferous crops are grown. It is one of the important diseases of rapeseed-mustard in India causing a yield loss of 17-34 per cent (Yadava et al., 2014). The disease is characterized by both local and systemic symptom expression. Local infection appears as white or creamy yellow pustules or "blisters" on leaves and stems. Systemic infection results in abnormal growth and distortion of inflorescence and sterility of flowers, commonly called stag head formed as a result of hypertrophy and hyperplasia. The epidemic development of white rust caused by A. candida is dependent upon many factors, viz. aggressiveness of race, amount of available initial inoculum, time of first appearance of the disease and prevailing weather conditions. A. candida isolates from different Brassica species/cultivar or from different geographical regions may be different in their incubation period, latent period and production of sporangia and zoospores, pustule size, shape and texture and aggressiveness (Lakra and Saharan, 1988; Gupta and Saharan, 2002; Patni et al., 2005 and Mishra et al., 2009).

\section{Materials and Methods}

\section{Symptomatology of the disease}

A survey was made at oil seed farm of university and three adjoining area of Kanpur viz. Ghatampur, Chaubepur and Sarsaul. In survey the affected fields were examined to know the disease severity in those locations. Observations were recorded on the basis of leaf area affected and severity of disease was noted. The shape, size, colour and arrangement of pustules were also noted on particular plants. The disease development was observed from starting of disease to severe condition, from local infection to systemic infection. The observations were made on different plant parts like leaf, stem and inflorescence. In this series observation were also made on impact of disease on growth and development of a plant internally and externally. Small creamy white spot on cotyledons can be seen. Downy growth of fungus appears on leaves, stem and on stage heads formed by white rust pathogen, Albugo candida. Mixed infection of white rust and downy mildew is common on stage heads.

\section{Screening of mustard germplasm for disease resistance}

Thirty germplasm of rapeseed-mustard groups (Brassica juncea, Brassica carinata, Brassica napus, Eruca sativa and B. rapa) were carried out during Rabi 2015-2016 under artificial 
conditions. In order to promote a severe natural epidemic of disease, the planting of $3 \mathrm{~m}$ double line of highly susceptible variety "Varuna" was incorporated after each five rows. The genotypes were gown in two rows each of $3 \mathrm{~m}$ length with spacing of $40 \times 10 \mathrm{~cm}$ in R.B.D. The recommended agronomic practices were adopted for raising a good crop.

Scale (0-9) for rating reaction to white rust:

$$
\begin{array}{ll}
0- & \text { (Immune) = nill } \\
1- & (\mathrm{HR})=\text { less than 5\% } \\
3- & (\mathrm{R})=5-10 \% \\
5- & (\mathrm{MR})=11-25 \\
7- & (\mathrm{S})=26-50 \% \\
9- & (\mathrm{HS})=\text { more than } 50 \%
\end{array}
$$

HR- Highly Resistant, R-Resistant, MRModerately Resistant, S- Susceptible, HSHighly Susceptible.

It is clear from the Table 1 that out of 30 genotypes tested nine genotype viz., Bioysr, DRMRIJ 12-14, DRMRIJ 12-39, DRMRIJ 12-48,DRMRJA 35,DRMRIJ 12-44, DRMRIJ 12-26, DRMRIJ 12-28 and DRMRIJ 12-40, were found free from the disease. Remaining genotypes were found as moderately susceptible, susceptible and highly susceptible against the white blister.

\section{Morphological characters of the pathogen}

The Albuginaceae includes the fungus known as white rust or blister. All of them are obligate parasites causing disease of vascular plants. Appearance of the pustules on the lower surface of the leaf as the deposition of the sporangium and sporangiophore which is creamy white in colour and hairy. Mycelium is endophytic, branched, hyline and having knob shaped haustoria. Sporangiophores in the beginning are sub epidermal and are clavate and simple. Lateral wall of sporangiophore is thickened but laterally they are free from the sporangia, which form in a basipetal chain and are attached with each other with a gelatiomous pad known as disjunctor.as the sporangia mature ,they become detached from the disjunctor and are free in the space between the sporangiophore and the epidermis of host. Upon the bursting of the epidermis, the sporangia are released and form a white crust on the surface of the host. Individually the sporangia are normally globose but pressure during their formation results in flattened sides so that some of tham are cuboids or polyhedral. The sporangia of Albugo germinate by zoospore or by germ tubes depending on the temperature. When zoospore are produced, the sporangia extrude 4-12 zoospore.

\section{Disease management}

The experiment was conducted at Oilseed Farm, Kalyanpur of the University during Rabi session 2015 - 2016. The Susceptible variety "Varuna" was sown at spacing of $40 \mathrm{x}$ $10 \mathrm{~cm}$. between row and plant in $3 \mathrm{~m} \times 5 \mathrm{~m}$ plot size. All recommended agronomical practices were adopted.

The trail was conducted with 10 treatments of different combination of different fungicides as foliar spray. The fungicides were collected from Department of Plant Pathology of the university. Details of treatments have been presented as follows:-

$\mathrm{T} 1$ - Single spray of mancozeb $(0.2 \%)$.

T2 - Single spray of metalaxyl. $8 \%+$ mencozeb 64\%WP (0.2\%).

T3 - Single spray of Hexaconazole 25EC $(0.05 \%)$.

T4 - Single spray of Difenconazole 25EC $(0.05 \%)$. 
T5 - Single spray of Propiconazole 25EC $(0.05 \%)$.

T6 - T1 followed by T2.

$\mathrm{T} 7$ - T1 followed by T3.

$\mathrm{T} 8$ - T1 followed by $\mathrm{T} 4$.

T9 - T1 followed by T5.

T10 - Control (water spray).

Data presented in the table 2 revealed that all the treatments were found significantly effective in reducing the disease intensity and increasing the yield over the control during the year (2015-2016). Single spray of propiconazole dose was superior over all the treatments, resulting in to lowest disease (17\%) and given maximum yield (1361.033).

T9-T1 fallowed by T5 was second best treatments over control which decreases the disease up to $20 \%$ and increase the yield $1266.60 \mathrm{~kg} / \mathrm{ha}$. Other treatment followed similar way of disease intensity and yield in decreasing order, which were significantly higher over control.

\section{Effect of different combination on yield}

The average yield data which is presented in Table- 3 indicates that, the maximum yield $1361.033 \mathrm{~kg} / \mathrm{ha}$ was obtained from single spray of propiconazole $25 \mathrm{EL}(0.05 \%)$ treated plots. The average yield from others treatments such as $\mathrm{T}_{1}$ followed by $\mathrm{T}_{5}, \mathrm{~T}_{1}$ fallowed by $\mathrm{T}_{3}$, single spray propiconazole 25 EC (0.5\%), yield was obtained 1266.60 $\mathrm{kg} / \mathrm{ha}, 1255.50 \mathrm{~kg} / \mathrm{ha}, \quad 1244.36 \mathrm{~kg} / \mathrm{ha} . \quad$ Field, respectively the yield obtained from $\mathrm{T}_{3}$ and $\mathrm{T}_{8}$ was $1177.70 \mathrm{~kg} / \mathrm{ha}$ and $1155.50 \mathrm{~kg} / \mathrm{ha}$ field, respectively which is significantly differ from $\mathrm{T}_{2}, \mathrm{~T}_{4}$ and $\mathrm{T}_{6}$ gave $1088.33 \mathrm{~kg} / \mathrm{ha}, 1033.26$ $\mathrm{kg} / \mathrm{ha}$, and $1033.266 \mathrm{~kg} / \mathrm{ha}$, respectively over the control (811.06 kg/ha.).

\section{Results and Discussion}

Keeping in view the importance of this fungus, the present investigation on symptoms and management of white blister (Albugo candida) of Indian mustard was carried out to investigate more suitable, ecofriendly substances for the effective management of this disease. During the investigation botanicals, organic amendment, bio-agents and metalaxyl were used in field experiment for white blister management.

Among the disease management approaches, the use of resistant varieties is considered to be the best and cheapest method of managing the plant disease. The present study was therefore, carried out for finding out the source of resistance against white blister of rapeseed- mustard caused by Albugo candida, under artificial conditions and results are presented. It is clear then the results that out of 30 genotype cultivars were tested, none was found free to this disease. Nine genotype viz., Bioysr and DRMRIJ-12-14, DRMRIJ 12-39, DRMRIJ-12-48, DRMRJA 35, DRMRIJ 12-44, DRMRIJ 12-26, DRMRIJ 12-28 and DRMRIJ 12-40 were observed to be moderately resistant to the disease. Remaining genotypes were found as moderately susceptible, susceptible and highly susceptible, against the white blister.

Evaluation of different fungicides, chemical and bio-agent with different combination viz., Single spray of propiconazale 25EC $(0.5 \%)$, single spray metalaxyl $8 \%$ mencozeb $64 \%$ wp $(0.2 \%)$, single spray of hexaconazole 25EC $(0.05 \%)$, single spray of Difenconazole 25EC $(0.05 \%)$, single spray propiconazole 25EL $(0.05 \%) \mathrm{T} 1$ followed by T2, T7- T1 followed by $\mathrm{T} 3 \mathrm{~T} 8-\mathrm{T} 1$ followed by $\mathrm{T} 4, \mathrm{~T} 9-\mathrm{T} 1$ followed by T5, T10 - Control. 
Table.1 Screening of Brassica germplasm and breeding material against white rust /blister of mustard under artificial condition

\begin{tabular}{|c|c|c|}
\hline Sr. No. & Entries & White rust Disease intensity (\%) \\
\hline 1 & Bioysr & $0.000(0.284)$ \\
\hline 2 & Rohini & $55.200(47.987)$ \\
\hline 3 & DRMRIJ 12-51 & $20.400(26.824)$ \\
\hline 4 & DRMRIJ 12-02 & $18.800(26.664)$ \\
\hline 5 & DRMRIJ 12-27 & $29.500(32.810)$ \\
\hline 6 & RH 1231 & $38.400(38.288)$ \\
\hline 7 & DRMRIJ 12-41 & $41.500(40.105)$ \\
\hline 8 & DRMRIJ 12-14 & $0.000(0.284)$ \\
\hline 9 & DRMRIJ 12-39 & $0.000(0.284)$ \\
\hline 10 & DRMRIJ 2035 & $43.200(41.085)$ \\
\hline 11 & DRMRIJ 12-48 & $0.000(0.284)$ \\
\hline 12 & DRMRIJ 12-06 & $33.200(35.165)$ \\
\hline 13 & RMWR-09-05-01 & $43.300(41.135)$ \\
\hline 14 & DRMRJA 35 & $0.000(0.284)$ \\
\hline 15 & DRMRIJ 12-44 & $0.000(0.284)$ \\
\hline 16 & DRMRIJ 12-03 & $51.00(45.755)$ \\
\hline 17 & RH 305 & $15.500(23.091)$ \\
\hline 18 & DRMRIJ 12-21 & $58.200(49.827)$ \\
\hline 19 & DRMRIJ 12-37 & $56.400(48.689)$ \\
\hline 20 & NPJ 181 & $15.500(23.178)$ \\
\hline 21 & DRMRIJ 12-26 & $0.000(0.284)$ \\
\hline 22 & RMWR-09-05 & $20.400(26.824)$ \\
\hline 23 & DRMR-2019 & $45.500(42.468)$ \\
\hline 24 & DRMRIJ 12-50 & $48.500(44.130)$ \\
\hline 25 & RH 1234 & $18.500(25.447)$ \\
\hline 26 & DRMRIJ 12-28 & $0.000(0.284)$ \\
\hline 27 & NDRE-08-14-01 & $50.100(45.053)$ \\
\hline 28 & DRMRIJ 12-65 & $33.500(35.341)$ \\
\hline 29 & DRMRIJ 12-43 & $16.600(24.002)$ \\
\hline \multirow[t]{3}{*}{30} & DRMRIJ 12-40 & $0.000(0.284)$ \\
\hline & CV & 11.696 \\
\hline & CD at 5\% & 6.1 \\
\hline
\end{tabular}

Table.2 Effect of different combination of the fungicide for the management of white blister

\begin{tabular}{|c|c|c|c|}
\hline Treatment & White blister disease (\%) & Yield kg/ha. & 1000 seed wt. \\
\hline T1 & $31.800(34.226)$ & 1244.366 & 4.388 \\
\hline T2 & $34.000(35.646)$ & 1088.833 & 4.341 \\
\hline T3 & $28.400(32.194)$ & 1177.700 & 4.812 \\
\hline T4 & $29.733(33.027)$ & 1033.266 & 4.814 \\
\hline T5 & $17.000(24.347)$ & 1361.033 & 4.90 \\
\hline T6 & $30.333(33.398)$ & 1033.266 & 4.336 \\
\hline T7 & $21.266(27.434)$ & 1255.500 & 5.082 \\
\hline T8 & $28.400(32.172)$ & 1155.500 & 4.628 \\
\hline T9 & $20.533(26.921)$ & 1266.600 & 4.728 \\
\hline T10 & $59.866(50.699)$ & 811.066 & 4.024 \\
\hline CV & $\mathbf{5 . 3 0 3}$ & $\mathbf{1 0 . 2 8 0}$ & \\
\hline CD at 5\% & $\mathbf{3 . 0 0 1}$ & $\mathbf{2 1 2 . 2 4}$ & \\
\hline
\end{tabular}


Table.3 Effect of different combination of fungicide yield data

\begin{tabular}{|c|c|c|}
\hline Treatment & Yield kg/ha. & Increase percent in yield \\
\hline T1 & 1244.366 & 53.42 \\
\hline T2 & 1088.833 & 34.24 \\
\hline T3 & 1177.700 & 45.20 \\
\hline T4 & 1033.266 & 27.39 \\
\hline T5 & 1361.033 & 67.80 \\
\hline T6 & 1033.266 & 27.39 \\
\hline T7 & 1255.500 & 54.79 \\
\hline T8 & 1155.500 & 42.46 \\
\hline T9 & 1266.600 & 56.17 \\
\hline Control & 811.066 & \\
\hline CV & $\mathbf{1 0 . 2 8 0}$ & \\
\hline CD & $\mathbf{2 1 2 . 2 4}$ & \\
\hline
\end{tabular}

The efficacy of different combination against white blister, all the treatments were found significantly effective in reducing the disease intensity and increasing the yield over the control against white blister of mustard (Albugo candida) in field condition. Among the treatments $\mathrm{T} 1$ fallowed by $\mathrm{T} 5$ showed maximum improvement in plant growth parameter (disease severity and percent disease control) and reduction of the white blister of mustard. At the maximum disease severity (20.533) and (21.266) was observed data $\mathrm{T} 1$ fallowed by $\mathrm{T} 5$ followed by $\mathrm{T} 1$ followed by T3. The maximum yield (1266.600 kg/ha) was obtained from $\mathrm{T} 1$ fallowed by $\mathrm{T} 5$, followed by $\mathrm{T} 1$ followed by T3 (1255.500 kg/ha).

The present study was therefore, carried out for finding out the source of resistance against white blister of rapeseed- mustard caused by Albugo candida, under artificial conditions and results are presented. It is clear then the results that out of 30 genotype cultivars were tested, none was found free to this disease. Remaining genotypes were found as moderately susceptible, susceptible and highly susceptible, against the white blister. Evaluation of different fungicides, chemical and bio-agent with different combination the efficacy of different combination against white blister, all the treatments were found significantly effective in reducing the disease intensity and increasing the yield over the control against white blister of mustard (Albugo candida) in field condition. Among the treatments $\mathrm{T} 1$ fallowed by $\mathrm{T} 5$ showed maximum improvement in plant growth parameter (disease severity and percent disease control) and reduction of the white blister of mustard.

\section{References}

Gupta, K., and Saharan, G.S. 1998. A Study of the epidemiology of Albugo candida disease of brassiceae. Ann. Appl. Biol., 40: 262-283.

Gupta, K., and Saharan, G.S. 2002. Identification of pathotype of Albugo candida with stable characteristic symptoms on Indian mustard. J. Mycol. Pl. Pathol. 32: 46-51.

Kolte, S.J., 1985. Diseases of Annual Edible Oilseed Crops, Vol. II, RapeseedMustard and Sesame Diseases. CRC Press Inc. Boca Raton, Florida, USA, p. 135.

Mishra, K.K., Kolte, S.J. Nashaat, N.I. and Awasthi, R.P. 2009. Pathological and 
biochemical changes in Brassica juncea (mustard) infected with Albugo candida (white rust). Pl. Pathol. 58: 80-86.

Patni, C.S., Singh, A. and Awasthi, R.P. 2005. Variability in Albugo candida causing white rust disease of rapeseed-mustard. J. Res. 4: 20-24.

Saharan, G.S., 1991. Assessment of losses, epidemiology and management of black spot disease of rapeseed-mustard. Proc. GCIRC 8th Int. Rapeseed Congr,
Saskatoon, Canada, p 84 (Abstr.). Vol. 2, 465-470.

Saharan, G.S., Kaushik, C.D. Gupta, P.P. and Tripathi, N.N. 1984. Assessment of losses and control of white rust of mustard. Indian Phytopath. 37, 397.

Yadav, R.B., Kumar, A. Kumar, A. and Verma, S.K. 2014. Screening of rapeseed-mustard cultivars/lines for resistance against alternaria blight. Indian J. Sci. Res. 5(1): 89-91.

\section{How to cite this article:}

Abhishek, Rajendra Prasad, Dushyant Kumar, Virendra Kumar, Maneesh Kumar and Deepak Kumar. 2017. Symptoms and Management of White Rust/ Blister of Indian Mustard (Albugo candida). Int.J.Curr.Microbiol.App.Sci. 6(10): 1094-1100.

doi: https://doi.org/10.20546/ijcmas.2017.610.133 